\title{
Análise da Importância da Responsabilidade Socioambiental como Fator Competitivo em uma Fábrica de Material de Limpeza em Juazeiro do Norte - CE
}

José Henrique da Silva Lopes ${ }^{1}$; Adriana Vigolvino Medeiros ${ }^{2}$; Maria Patrícia de Alencar ${ }^{3}$;osé Leandro de Almeida Neto ${ }^{4}$

Resumo: Atualmente, na incessante busca pelo aumento da competitividade, as organizações por vezes deixam em segundo plano as questões ambientais e sociais, negligência percebida como falta de responsabilidade socioambiental. Vale salientar que, na maioria das vezes, as práticas de responsabilidade social empresarial são vistas como custos altos e desnecessários. Diante disso, este trabalho tem como objetivo investigar a importância da prática de responsabilidade socioambiental como diferencial estratégico do ponto de vista dos gestores de uma empresa fabricante de materiais de limpeza. Para isso foram realizadas entrevistas com os gestores da referida indústria, que é referência na região, por adotar e ter na sua cultura a responsabilidade social e ambiental. Foi investigado como esta consegue ter cada vez mais sucesso cuidando do meio ambiente e ajudando a sociedade, e verificou-se que a mesma consegue traçar estratégias de crescimento através da adoção de práticas socioambientais. Depois de coletadas as informações foram identificados os pontos principais das respostas obtidas e foram criados indicadores que geraram quadros para análise das informações, contendo os dados colhidos na pesquisa e sua respectiva interpretação. Através de uma análise de discurso, tratando as informações colhidas dentro da fala dos sujeitos abordados, os dados foram analisados de maneira individual e também coletiva, unindo em uma síntese o que foi relatado na entrevista pelos abordados, fazendo-se uma avaliação geral dos aspectos descritos.

Palavras-chave: Administração. Responsabilidade Social. Sustentabilidade.

\section{Analysis of the Importance of Socio-Environmental Responsibility as a Competitive Factor in a Cleaning Material Factory in Juazeiro do Norte - CE}

\begin{abstract}
Today, companies are constantly looking for new ways to become more competitive, forgetting, in the process, about the importance of the environment, as well as the social environment in which they are inserted, leading to problems related to socio-environmental responsibility. It is worth noting that, in most cases, practices aimed at corporate social responsibility are seen as high and unnecessary costs. The objective of this work is to investigate the importance of the practice of social and environmental responsibility as a strategic advantage from the point of view of the managers of a company that manufactures cleaning materials. For this purpose, interviews were conducted with the managers of the mentioned industry, which is a reference in the region for adopting as part of their core value, culture social and environmental responsibility. It was investigated how this industry can be more successful by taking care of the environment and helping society, and it has been verified that it can draw
\end{abstract}

\footnotetext{
${ }^{1}$ Bacharel em Administração pelo Centro Universitário Dr. Leão Sampaio/UNILEÃO, Juazeiro do Norte-CE, Brasil, henriqueprofiletwo@hotmail.com

${ }^{2}$ Mestre em Engenharia de Produção pela Universidade Federal de Pernambuco (UFPE), Professora do Centro Universitário Dr. Leão Sampaio/UNILEÃO, Juazeiro do Norte-CE, Especialista em Planejamento e Gestão Organizacional e Gestão da Qualidade em Serviços pela Universidade Estadual de Pernambuco (UPE) e adrianamedeiros@ leaosampaio.edu.br

${ }^{3}$ Bacharel em Administração pelo Centro Universitário Dr. Leão Sampaio/UNILEÃO, Juazeiro do Norte-CE, Brasil, patriciaalencar133@gmail.com

${ }^{4}$ Mestrando em Desenvolvimento Sustentável pela Universidade Federal do Cariri (UFCA), Professor do Centro Universitário Dr. Leão Sampaio/UNILEÃO, Coordenador dos Cursos de Gestão de Recursos Humanos e Gestão Comercial na Unileão, Juazeiro do Norte-CE, Brasil, leandro@leaosampaio.edu.br
} 
growth strategies through the adoption of socio-environmental practices. After the information was collected, the main points of the answers were identified and indicators were created that, in turn, generated tables for analysis of the information. Through a discourse analysis, the data were analyzed individually and also collectively, resulting in a synthesis of what was reported in the interview by the subjects, making a general evaluation of the aspects described.

Keywords: Management. Social Responsability. Sustainability.

\section{Introdução}

Atualmente, as empresas vivem em busca constante de novas maneiras de se tornarem mais competitivas, esquecendo, às vezes da importância do meio ambiente, como também da sociedade na qual estão inseridas, o quê ocasiona, muitas vezes, problemas com relação a responsabilidade socioambiental.

O desafio comum em todas estas organizações é encontrar uma maneira de se destacar em relação as outras. Diante deste canário, uma estratégia bem elaborada, alinhada com diretrizes sócio ambientais é fundamental para melhorar a competitividade das organizações, atraindo a atenção do consumidor de outras maneiras que não se limite apenas ao produto e ao preço. Tenório (2006 apud Andrade; Gosling; Jordão, 2013), descreve que vários fatores levaram as empresas a se tornarem corporações socialmente responsáveis, de maneira que estes precisam ser vistos de forma conjunta.

Por outro lado, sabe-se que ser uma empresa sustentável e responsável socialmente não é um processo simples e pode gerar altos custos. Ser sustentável é um desafio que praticamente todas as organizações almejam, para Valente (2012 apud Scholl; Hourneaux Jr; Galleli, 2015) a sustentabilidade precisa representar uma nova maneira de agir da empresa em resposta às necessidades dos stakeholders, visando sempre a melhoria da relação entre seus processos e o meio social.

Assim, o objetivo geral desta pesquisa é identificar a importância da responsabilidade socioambiental como fator competitivo do ponto de vista dos gestores de uma empresa fabricante de materiais de limpeza, localizada na cidade Juazeiro do Norte - CE. A empresa objeto do estudo é referência na região por adotar e ter na sua cultura responsabilidade social e ambiental. Foi investigado como esta consegue ter cada vez mais sucesso cuidando do meio 
ambiente e ajudando a sociedade, e verificou-se que a mesma consegue traçar estratégias de crescimento através da adoção de práticas socioambientais. Para isso foi realizada uma entrevista com gestores da empresa, cada qual apresentando informações de pontos de vista distintos.

Este trabalho teve como base de dados a pesquisa bibliográfica, que para Gil (2010, p. 29) "é elaborada com base em material já publicado [...] inclui material impresso como livros, revistas, jornais, teses, dissertações e anais de eventos científicos”. Posteriormente para confrontar a teoria com a prática foi feita uma pesquisa qualitativa exploratória, que buscou identificar as diferentes visões de gestores da empresa alvo da pesquisa à cerca da responsabilidade socioambiental praticadas na organização.

Depois de coletadas as informações foram identificados os pontos principais das respostas obtidas e foram criados indicadores que geraram quadros para análise das informações, contendo os dados colhidos na pesquisa e sua respectiva interpretação. Através de uma análise de discurso, tratando as informações colhidas dentro da fala dos sujeitos abordados, os dados foram analisados de maneira individual e também coletiva, unindo em uma síntese o que foi relatado na entrevista pelos abordados, fazendo-se uma avaliação geral dos aspectos descritos.

Este estudo torna-se importante por introduzir conhecimento a respeito de como uma empresa pode implementar praticas de responsabilidade socioambiental e ainda sim, ser uma empresa lucrativa. Pesquisar dentro desta área de estudo torna-se também imprescindível uma vez que as práticas ambientais ou sociais por muito tempo foram vistas dentro das organizações como custos sem retorno, no entanto se mais estudos se aprofundarem nesta área torna-se possível utilizá-las como fator estratégico e competitivo dentro do mercado.

\section{Referencial Teórico}

\section{Responsabilidade Social Empresarial}

Segundo Aligreli; Aligreli; Kruglianskas (2009) as discussões sobre responsabilidade social das empresas seguem modelos que buscam o equilíbrio entre o social e o funcional, ou seja, tentar encontrar maneiras de produzir de forma equilibrada onde se possa ter o controle 
dessa produção evitando causar mais danos ao meio em que estas organizações se encontram inseridas. A ideia de responsabilidade social da empresa se alterna sobre as relações entre a empresa e a sociedade. (ACQUIER e AGGERI, 2008).

De acordo ainda com Aligreli; Aligreli; Kruglianskas (2009), o conceito de Responsabilidade Social passa por evoluções constantes e configurações que englobam diversos fatores, levando em conta principalmente a visão da sociedade em si formada pelos stakeholders (indivíduos que tenham intervenção direta nos processos da empresa) em relação ao que as empresas estão fazendo para analisar e controlar os impactos sociais causados pela execução de seus processos produtivos. Zanitelli (2013) classifica como Responsabilidade Social da Empresa tanto a atividade de cumprimento das determinações legais como a que vai além deste cumprimento, isto implica que a Responsabilidade Social da Empresa está diretamente ligada a filantropia social, o agir além do que a legislação designa.

A Responsabilidade Social Empresarial (RSE) foi definida por Reynaud (2008) como a uma forma de identificar e atender os interesses daqueles que são afetados pelas ações da organização, ou seja, satisfazer a necessidade direta dos membros envolvidos pelos processos da empresa. Aligreli; Aligreli; Kruglianskas (2009) relata que a Responsabilidade Social Empresarial (RSE) é uma percepção por parte das empresas das consequências de suas ações na sociedade e para a sociedade, seguida pelas execuções de ações sociais que possam minimizar o impacto social dos processos realizados pela mesma, onde os Stakeholders tem papel fundamental na existência de empresas socialmente responsáveis, pois são eles que participam diretamente de todos os processos observando e percebendo as ações de cunho social executadas por estas.

Até meados do século XX predominou a visão de que a empresa precisava se adaptar à visão do Shareholder (acionistas e investidores), as ações das empresas precisavam estar posicionadas a favorecer quem nelas investiam, discorrendo que no modelo de Friedman de 1963 a organização deveria focar exclusivamente no contexto econômico buscando o lucro, enfatizando os benefícios trazidos para a empresa e para a sua estabilidade econômica, assim poderia lucrar mais, gerar mais empregos, pagar impostos e por fim tornar-se-ia uma empresa socialmente responsável por que estaria beneficiando a sociedade com mais geração de renda assim como o governo por estar agindo de maneira correta com suas obrigações tributárias. (ALIGRELI; ALIGRELI; KRUGLIANSKAS, 2009). 
Indo ao contrário disto, Reynaud (2008), discorre que no modelo de Freeman de 1984, a satisfação das partes interessadas é o que garante o bom funcionamento dos processos da empresa e, dessa forma, o seu rendimento final, isto é, neste modelo a relação empresa e sociedade não se limita apenas aos investidores, e sim a todos que de alguma maneira interfiram no seu processo, se a organização consegue atender as necessidades desses stakeholders, ela torna-se um empresa lucrativa e detentora da Responsabilidade Social.

De acordo com Dias (2011) a Responsabilidade Social está relacionada principalmente a ações que vão além da legislação, melhor dizendo, uma empresa considerada responsável em contexto social precisa executar práticas que não estejam apenas contidas na lei com intuito de preservar a integridade tanto dos próprios colaboradores quanto do ambiente em que está, como também e principalmente dos seus próprios clientes, nesta visão a Responsabilidade Social se atrela a filantropia social deixando claro que existe diferença entre uma empresa que faz uma doação para uma instituição de caridade ocasionalmente e uma empresa socialmente responsável.

Segundo Ethos (2000 apud Andrade; Gosling; Jordão, 2013) a caracterização de Responsabilidade Social está atrelada notoriamente à compreensão que as ações da empresa devem beneficiar necessariamente à sociedade, assim como proporcionar a realização profissional dos colaboradores, promover benefícios para seus parceiros e também para o meio ambiente, dessa maneira trazendo lucro para os seus Shareholders, seus acionistas e investidores.

\section{Contexto Histórico da Responsabilidade Social Empresarial como Fator Competitivo}

Na visão de Tenório (2006 apud Andrade; Gosling; Jordão, 2013), vários fatores levaram as empresas a se tornarem corporações socialmente responsáveis, de maneira que estes precisam ser vistos de forma conjunta, o primeiro deles foi a falência do bem-estar social, isto é, o meio que antes fluía bem como sociedade começou a apresentar diversos problemas que claramente eram provocados por irresponsabilidades das empresas e também das pessoas.

Outro fator primordial que fez com que as empresas parassem para pensar melhor nas suas ações voltadas a RSC (Responsabilidade Social Corporativa), para Carrol (1999 apud 
Andrade; Gosling; Jordão, 2013) foi o despertar do mundo para aos problemas ambientais que despontaram juntamente com o surgimento das novas tecnologias, com isso a mídia teve um gigantesco desenvolvimento. Era notório que as corporações precisavam fazer alguma coisa para não ficarem marcadas como empresas que não se importavam com o bem-estar da população e do próprio planeta. Todos esses fatores em conjunto propiciaram um ambiente favorável para que a Responsabilidade Social deixasse de ser um fator filantrópico e passasse a ser um fator estratégico no contexto competitivo do mercado, como relata:

[...] o desenvolvimento da RSC tem a ver com a combinação de uma série de elementos que precisam ser vistos em conjunto. O primeiro deles relaciona-se com a falência do estado de bem-estar social [...]. Outras questões, contudo, também ajudaram a construir o painel atual sobre o assunto. Dentre as mais importantes, destacam-se: os problemas de ordem ambiental que acentuaram-se nas últimas décadas; o desenvolvimento de novas mídias; o aumento de escolaridade e consciência da população, especialmente em países de alto desenvolvimento humano; dentre outros. (CARROL, 1999 apud ANDRADE; GOSLING; JORDÃO, 2013, p. 793).

Como a competição dos mercados tornou-se muito acirrada devido à revolução tecnológica que ocorreu nos últimos anos, encontrar maneiras de se destacar diante da concorrência tornou-se uma corrida para as organizações, de acordo com Aligreli; Aligreli; Kruglianskas (2009) preço, produtos e serviços de qualidade não eram mais suficientes para se conseguir destaque no mercado, pois os consumidores precisavam enxergar a empresa como uma marca dentro do mercado que busca trazer constantes inovações sempre com intuito de minimizar os danos causados por suas operações.

No entanto o mercado não foi o único a se tornar mais complexo, para Tachizawa (2005) o novo contexto econômico trouxe uma postura mais rígida dos próprios clientes, os quais sentiam a maior necessidade de interagir com empresas que eram éticas e tinham boa imagem no mercado, isto é, a imagem que a organização passa para o consumidor em relação à sua ética social tornou-se um importante critério de escolha para os clientes, superando muitas vezes aspectos como preço e qualidade dos produtos ou na prestação de serviços.

Assim é possível identificar que os processos produtivos foram obrigados a sofrer grandes mudanças, se for pensado que o próprio ciclo de vida dos produtos foi encurtado, isso fez com que as empresas fizessem da reputação o mais importante atributo da marca, sendo isto fundamental para a retenção e conquista de novos mercados, reputação que era baseada principalmente na imagem da empresa para os stakeholders, que nesse contexto englobam 
clientes, fornecedores, governos, acionistas, organizações não governamentais, mídia, colaboradores e os próprios concorrentes, isto implica dizer que as empresas para se manterem competitivas precisam estar almejando constantemente melhorar sua imagem para diversos atuantes diferentes, onde cada um possui uma visão voltada a um foco (ALIGRELI; ALIGRELI; KRUGLIANSKAS, 2009).

\section{Sustentabilidade}

De maneira geral Sustentabilidade é o que relaciona a busca das satisfações das necessidades da geração atual, sem o comprometimento da capacidade das gerações futuras de satisfazerem as suas próprias necessidades (WCED, 1987). Assim para Freitas (2012), Sustentabilidade é o direito que todos têm de aspirar a um futuro.

Ser sustentável é um desafio que praticamente todas as organizações almejam, para Valente (2012 apud Scholl; Hourneaux Jr; Galleli, 2015) a sustentabilidade precisa representar uma nova maneira de agir da empresa, não unicamente se basear em práticas voluntárias em resposta às necessidades dos stakeholders, além disso, uma empresa sustentável deve demonstrar a inclusão de aspectos sociais aos seus processos visando sempre a melhoria da relação entre seus processos e o meio social.

Van Marrewijk; Werre (2003 apud Scholl; Hourneaux Jr; Galleli, 2015) afirma que partindo disso a Sustentabilidade Organizacional se refere às atividades da empresa que demonstram a inclusão de aspectos sociais e ambientais às suas operações econômicas e interações com stakeholders. De acordo com Rattner (1999 apud MENDES, 2009, p. 53) "o argumento de economistas a favor da sustentabilidade gira em torno de saber usar os recursos do planeta, com alocação eficiente de recursos naturais em um mercado competitivo". Foladori (2002 apud Mendes, 2009, p. 52) acrescenta a ideia de que:

[...] a sustentabilidade ecológica é a que suscita menos controvérsias, uma vez que se refere a certo equilíbrio e à manutenção dos ecossistemas, conservação e manutenção genética, incluindo, também, a manutenção dos recursos abióticos e a integridade climática. Este conceito aborda a natureza externa ao ser humano e a concepção de que quanto mais modificações realizadas pelo homem na natureza menor sua sustentabilidade ecológica e quanto menor a interferência humana na natureza, maior sua sustentabilidade. 
Entende-se que a sustentabilidade econômica apresenta uma análise mais complexa do que a ambiental, pois o conceito restringe o crescimento econômico e a eficiência produtiva, essa concepção admite que o crescimento não pode ser ilimitado, pois não é congruente com a dimensão ambiental, as empresas não devem seguir o ideal de que o seu avanço no mercado é ilimitado independentemente das condições ambientais, pois o seu crescimento está diretamente atrelado à capacidade do meio de fornecer recursos, assim o primeiro passo para a sustentabilidade econômica é associar o crescimento econômico da organização à capacidade de fornecimento de recursos do meio ambiente (FOLADORI, 2002 apud MENDES, 2009).

\section{Práticas Socioambientais}

\section{Destinação de Resíduos}

De acordo com Lima (1995 apud Soares, 2007) a coleta dos resíduos sólidos é a parte mais sensível ao ver da população, tornando a mais passível de crítica. Assim, faz-se necessário um planejamento bem elaborado e uma atuação eficiente do poder público nas ações de coleta e destinação dos resíduos gerados pelos habitantes, além de uma maneira sistemática de atuação, além do mais, precisa garantir requisitos como universalização de coleta e regularidade, o que compreende periodicidade, frequência e horário.

Basicamente esses dejetos gerados pelo homem são depositados em algum lugar, na maior parte das vezes inadequado como lixões ou aterros clandestinos, seguindo a legislação do país todos os munícipios brasileiros têm a obrigação de possuir um lugar adequado para disposição dos resíduos gerados, um aterro sanitário planejado e implantado em um local que não afete a integridade do ser humano habitante do meio nem o meio ambiente em si (VAZ; CABRAL, 2005).

\section{Coleta Seletiva}

Segundo Gonçalves (2005 apud Soares, 2007) a coleta seletiva é uma alternativa ecologicamente correta para a preservação do meio ambiente e melhoria da qualidade de vida 
da população. Trata-se de um processo de recolhimento de materiais recicláveis dividido por tipo de material, em que os resíduos são depositados em recipientes separados pela própria fonte geradora, no caso os próprios cidadãos. A Coleta Seletiva é de fundamental importância para minimização dos impactos gerados pela geração de resíduos sólidos

Conforme Logarezzi (2002 apud Massukado, 2004) quanto maior forem as frações que o lixo é separado mais eficiente se tornará o processo, pois os materiais estarão mais limpos, no entanto, o tempo gasto na coleta é maior, sendo necessário um elevado investimento inicial. Através disso percebe-se que a prática de coleta seletiva de resíduos não é uma técnica barata para o poder público e que, além disso, carece de colaboração da população para se tornar eficiente.

\section{Reciclagem}

Com tantas dificuldades de disposição desses dejetos e o crescente aumento da população e por consequência o aumento da geração de resíduos, a opção que se ver como mais limpa e alternativa seria a Reciclagem do lixo, que "é um conjunto de técnicas que tem por finalidade aproveitar os detritos e reutilizá-los no ciclo de produção de que saíram [...]" (VALLE, 2002 apud SOARES, 2007. p. 5). Dessa maneira, reciclar torna possível devolver à origem, na forma de matérias-primas, os materiais que não se degradam, isto é, materiais que iriam para o lixo, ou já estariam nele.

Para Fadini; Fadini (2005) o reaproveitamento dos resíduos antes de serem jogados fora, diminui o acúmulo desses materiais no meio ambiente e através disso a poluição ambiental é minimizada, melhorando a qualidade de vida dos habitantes. Assim conclui-se que a prática aliada a um esforço em comum da população é sinônimo de melhoria de vida.

\section{Procedimentos Metodológicos}

De início, este projeto teve como base de dados a pesquisa bibliográfica, que para Gil (2010, p. 29) “é elaborada com base em material já publicado [...] inclui material impresso como livros, revistas, jornais, teses, dissertações e anais de eventos científicos". Foram utilizadas 
informações colhidas em livros, revistas, sites confiáveis, dentre outros meios de aquisição de dados que tenham relevância para o tema abordado nesta pesquisa.

Para confrontar a teoria com a prática foi feita posteriormente uma pesquisa qualitativa exploratória, que buscou identificar as diferentes visões de gestores da empresa alvo da pesquisa à cerca da responsabilidade socioambiental praticadas na organização. Foram abordados o diretor geral, o diretor comercial e a engenheira química responsável pelas questões ambientais. Nas perguntas feitas aos entrevistados procurou-se identificar a importância dessas práticas como fator de competição de mercado para a organização. As informações e dados colhidos no estudo do processo foram então analisadas para observar a eficiência destas práticas.

Também na pesquisa, procurou-se investigar partir de qual momento a organização entendeu a relação entre competitividade e a responsabilidade socioambiental. Além disso, buscou-se entender de que forma, na visão dos gestores, a realização destas práticas pode impactar dentro da empresa, se utilizadas como um instrumento estratégico para a organização, além de tentar identificar a visão dos gestores em relação ao seu trabalho em uma organização responsável, analisando sua visão socioambiental.

O roteiro de entrevista foi composto por questões subjetivas. Depois de realizada a pesquisa com os gestores da empresa alvo do estudo, os dados coletados foram analisados através de uma análise de discurso e transcritos para o resultado. Posteriormente, ligando as informações recolhidas na pesquisa, foram interpretadas essas informações, e em seguida estes resultados foram analisadas sob a ótica da teoria publicada sobre o assunto e do objetivo do estudo.

\section{Análise e Discussão dos Resultados}

Depois de coletadas as informações foram identificados os pontos principais das respostas obtidas e foram criados indicadores que geraram quadros para análise das informações, contendo os dados colhidos na pesquisa e sua respectiva interpretação. Através de uma análise de discurso, tratando as informações colhidas dentro da fala dos sujeitos abordados, os dados foram analisados de maneira individual e também coletiva, unindo em uma síntese o que foi relatado na entrevista pelos abordados, fazendo-se uma avaliação geral dos aspectos descritos. 
O discurso é classificado por Fernandes (2007 apud Oliveira Jr.; Pacagnan; Marchiori, 2013) como pronunciamento político, estético ou vão, caracterizado por sua expressividade e formado por indícios aperfeiçoados, e como uma manifestação efetiva da língua, atribuída de essência e de definição socialmente construídos.

Para cada quadro foram criados indicadores que facilitaram a divisão dos dados, para que fosse possível fazer a comparação e assimilação das diferentes falas dos gestores.

QUADRO 01: Conhecimento dos gestores em relação à RSE.

\begin{tabular}{|c|c|c|}
\hline Sujeito & Discurso direto & Análise do discurso individual \\
\hline G1 & $\begin{array}{l}\text { "A Responsabilidade Social é um papel da } \\
\text { indústria que por ser um responsável pela } \\
\text { geração de poluentes deve direcionar bem estes } \\
\text { de maneira que não venha a prejudicar o meio } \\
\text { ambiente". }\end{array}$ & $\begin{array}{l}\text { Nota-se no relato que este gestor têm um } \\
\text { conhecimento da RSE, mas de uma maneira } \\
\text { não teórica e sim de forma bem prática, } \\
\text { citando que é um papel das empresas, } \\
\text { principalmente da indústria, cuidar do meio } \\
\text { ambiente levando em conta o fato de serem } \\
\text { os maiores geradores de agentes poluidores, } \\
\text { configurando uma ideia quase empírica, mas } \\
\text { bem prática das responsabilidades da } \\
\text { empresa com o meio socioambiental. }\end{array}$ \\
\hline G2 & $\begin{array}{l}\text { "Responsabilidade social é visualizada quando } \\
\text { empresas ou indústrias voluntariamente adotam } \\
\text { práticas que visam a melhora e o cuidado para } \\
\text { com a sociedade na qual estão inseridas". }\end{array}$ & $\begin{array}{l}\text { Percebe-se uma visão bem definida e } \\
\text { embasada a cerca deste conceito, mostrando } \\
\text { um relato científico que se assemelha aos da } \\
\text { Responsabilidade Social definido pelos } \\
\text { maiores escritores deste campo. }\end{array}$ \\
\hline G3 & $\begin{array}{l}\text { "A cada dia a humanidade vem degradando o } \\
\text { meio ambiente, muitas vezes por } \\
\text { desconhecimento, falta de cultura mesmo. Eque } \\
\text { representa uma empresa que tem seus produtos } \\
\text { todos os dias nos lares, temos a obrigação de } \\
\text { cuidar e ao mesmo tempo levar a } \\
\text { conscientização as pessoas do zelo com o meio } \\
\text { ambiente [...]". }\end{array}$ & $\begin{array}{l}\text { Um conceito empírico e pessoal, relata na sua } \\
\text { fala que as pessoas são responsáveis pela } \\
\text { degradação ambiental, relatando motivos } \\
\text { como até como "falta de cultura". } \\
\text { Complementa dizendo que empresas que tem } \\
\text { seus produtos todos os dias nos lares tem } \\
\text { como obrigação promover e conscientizar } \\
\text { esta Responsabilidade Social para com seus } \\
\text { colaboradores e clientes. }\end{array}$ \\
\hline \multicolumn{3}{|c|}{ Análise Coletiva } \\
\hline $\begin{array}{l}\text { Fazendo } \\
\text { pela pes }\end{array}$ & $\begin{array}{l}\text { análise dos discursos de maneira geral é possí } \\
\text { Im conceito empírico acerca da RSE, mostrand }\end{array}$ & $\begin{array}{l}\text { perceber que predomina entres os abordados } \\
\text { uma forma bem pessoal a preocupação desta } \\
\text { percebe um discurso científico, fica expresso }\end{array}$ \\
\hline
\end{tabular}

Fonte: Dados da Pesquisa (2017)

Analisando mais a fundo estas informações e percebendo a personalização da Responsabilidade Social dentro da empresa, torna-se possível enxergar o que foi relatado por Aligreli; Aligreli; Kruglianskas (2009), quando se percebe na fala da maior parte dos gestores 
o equilíbrio entre o social e o funcional, como citado pelo autor, fazendo com que a responsabilidade social se aplique não só dentro dos limites da empresa, mas que esta esteja inserida em todo o meio social, incluindo colaboradores e clientes, parte principal entre seus stakeholders.

No que se ver de científico na informação vinda dos sujeitos abordados, vê-se um conceito bem definido, assim como é relatado por Zanitelli (2013), de modo que a RSE, é segundo este o conjunto de ações realizadas por empresa que se preocupam com o meio socioambiental, de maneira voluntária, como relatado pelo gestor entrevistado.

QUADRO 02: Identificação das Práticas dentro da organização.

\begin{tabular}{|c|c|c|}
\hline Sujeito & Discurso Direto & Análise do Discurso Individual \\
\hline G1 & $\begin{array}{l}\text { "Reutilização de matéria prima defeituosa: } \\
\text { Embalagens defeituosas são trituradas e } \\
\text { reutilizadas na produção. } \\
\text { Reutilização de água do resfriamento: A água } \\
\text { utilizada no resfriamento das caldeiras antes de } \\
\text { voltar ao meio ambiente é tratada em ETE } \\
\text { (Estação de Tratamento de Esgoto), pois } \\
\text { acumula impurezas durante o processo". }\end{array}$ & $\begin{array}{l}\text { O gestor cita duas práticas de reciclagem } \\
\text { realizadas dentro da empresa, que ajudam de } \\
\text { maneira muito eficiente à preservação do } \\
\text { meio ambiente como também na redução de } \\
\text { desperdícios na produção. }\end{array}$ \\
\hline G2 & $\begin{array}{l}\text { "Projeto de recolhimento de óleo de cozinha } \\
\text { utilizado com valores revertidos em prol da } \\
\text { assistência as crianças com câncer assistidas } \\
\text { pelo IACC de Barbalha CE". }\end{array}$ & $\begin{array}{l}\text { É citado o principal projeto de } \\
\text { Responsabilidade social por parte desta } \\
\text { empresa, que também configura uma prática } \\
\text { de reciclagem, mas que vai bem além disso. }\end{array}$ \\
\hline G3 & $\begin{array}{l}\text { "Temos uma cultura de diminuir ao máximo o } \\
\text { desperdício de água, porém, a prática } \\
\text { socioambiental mais notável da nossa empresa } \\
\text { é a coleta e utilização de óleo de cozinha usado. } \\
\text { Além de retirarmos de circulação de um agente } \\
\text { poluidor do meio ambiente, revertemos o valor } \\
\text { do óleo doado para uma instituição de caridade } \\
\text { (IACC)". }\end{array}$ & $\begin{array}{l}\text { Mais uma vez citado esta prática de } \\
\text { reciclagem, percebe-se que é a mais lembrada } \\
\text { quando se fala sobre responsabilidade social } \\
\text { dentro desta organização. }\end{array}$ \\
\hline \multicolumn{3}{|c|}{ Análise Coletiva } \\
\hline \multicolumn{3}{|c|}{$\begin{array}{l}\text { No discurso geral dos gestores, mostrou-se uma grande percepção das práticas ambientais realizadas dentro } \\
\text { da empresa, destacando-se a reciclagem, processo que matérias-primas, ou recursos utilizados na produção } \\
\text { voltam a ser reutilizados. Nisso pode-se perceber uma grande preocupação da empresa com a preservação } \\
\text { ambiental, mas o destaque maior é para o projeto social citado no qual é revertido valores arrecadados com o } \\
\text { recolhimento de óleo de cozinha em doações para uma instituição de caridade que ajuda crianças com câncer } \\
\text { na cidade vizinha, mostrando-se a filantropia social, um dos pilares da RSE. }\end{array}$} \\
\hline
\end{tabular}

Fonte: Dados da Pesquisa (2017)

Através do que foi relatado, pode se perceber que a Reciclagem é a principal prática de preservação executada na empresa, sendo esta feita de várias formas dentro do processo 
produtivo e que todos os abordados percebem isto como um fator muito importante para uma organização que almeja ser responsável socialmente.

Também foi citado como objetivo da reciclagem de materiais dentro da empresa, a redução de gastos e do desperdício, fazendo voltar à produção detritos ou resíduos que dela saíram para que sejam reaproveitados, o que se assemelha a teoria de Valle (2002 apud SOARES, 2007) acerca do tema.

Levando em conta que cada gestor consegue ter a visão das ações promovidas e do comprometimento por parte da empresa para com a sociedade, é que se pode considerar esta uma empresa Responsável, pois não são práticas isoladas que são citadas na pesquisa, sim um conjunto em prol de um objetivo, esse comprometimento citado é o que propicia a filantropia social que é explicada anteriormente por Dias (2011).

QUADRO 03: Impacto das ações na empresa

\begin{tabular}{|c|c|c|}
\hline Sujeito & Discurso Direto & Análise do Discurso Individual \\
\hline G1 & $\begin{array}{l}\text { "É importante, pois contribui com a } \\
\text { preservação do meio ambiente como também da } \\
\text { própria sociedade fazendo com que empresas } \\
\text { possam além de ganhar melhor visibilidade } \\
\text { perante governo e sociedade consigam também } \\
\text { uma redução de danos ao meio no qual estão } \\
\text { inseridas e precisam estar em constante retirada } \\
\text { de recursos". }\end{array}$ & $\begin{array}{l}\text { O sujeito abordado aqui fala sobre a } \\
\text { importância das ações de uma forma que } \\
\text { estas geram uma melhor visão das pessoas } \\
\text { para com a empresa, promovendo uma } \\
\text { visibilidade positiva para e empresa, } \\
\text { preocupando-se então com a imagem da } \\
\text { empresa. Além disso, em sua fala demonstra } \\
\text { a preocupação com a redução de danos ao } \\
\text { ambiente, pois, necessitam do meio para } \\
\text { retirada de recursos. }\end{array}$ \\
\hline G2 & $\begin{array}{l}\text { "É muito importante como a empresa é vista } \\
\text { pelo mercado consumidor e as açôes que ela } \\
\text { pratica na sociedade formam um perfil de como } \\
\text { ela quer ser vista pelo seu público. Além disso, } \\
\text { contribui com a sociedade na qual está inserida, } \\
\text { formando uma imagem positiva a frente de seus } \\
\text { consumidores, colaboradores e demais } \\
\text { envolvidos nos processos". }\end{array}$ & $\begin{array}{l}\text { Vê-se outra vez a preocupação em primeiro } \\
\text { plano com a imagem da organização perante } \\
\text { a sociedade e aos consumidores, } \\
\text { preocupando-se em construir um perfil de } \\
\text { uma empresa preocupada com as questões } \\
\text { ambientais. Porém, há maior preocupação } \\
\text { com a imagem que quer construir na mente } \\
\text { do consumidor do que com os problemas } \\
\text { ambientais. }\end{array}$ \\
\hline G3 & $\begin{array}{l}\text { "Os clientes passam a ver com essas ações } \\
\text { realizadas uma empresa não só como uma } \\
\text { fornecedora de produtos de limpeza, mas } \\
\text { também como uma parceira social". }\end{array}$ & $\begin{array}{l}\text { Já na fala deste gestor, constata-se a } \\
\text { preocupação com o mercado consumidor, } \\
\text { mas de uma maneira muito benéfica quando } \\
\text { relata que almeja não ser vista apenas como } \\
\text { uma fornecedora de produtos, mas como } \\
\text { parceira social. }\end{array}$ \\
\hline \multicolumn{3}{|c|}{ Análise Coletiva } \\
\hline \multicolumn{3}{|c|}{$\begin{array}{l}\text { De maneira geral, fica bem explícito um discurso por parte dos gestores preocupados com a imagem da } \\
\text { empresa perante a sociedade, não deixando de lado a preocupação com os problemas ambientais, mas sim se } \\
\text { utilizando como uma ferramenta estratégica de marketing, tentando inserir na mente do consumidor a ideia de }\end{array}$} \\
\hline
\end{tabular}


que a organização seja uma parceira da sociedade, isso fica mais visível apenas na fala última do último gestor, enquanto nos anteriores constata-se uma visão bem mais preocupada com perfil e imagem da empresa.

Fonte: Dados da Pesquisa (2017)

Notavelmente a influência da responsabilidade social da empresa alvo do estudo é baseada na visão das pessoas em relação as ações, como relatou Reynaud (2008) acerca de que é preciso satisfazer os interesses daqueles que são afetados diretamente pelas ações da empresa. Quando é dito que isso propicia uma imagem positiva relembra o que cita Tachizawa (2005) quando descreve uma geração de clientes mais exigentes, pois segundo os sujeitos pesquisados essa imagem positiva só é alcançada quando o cliente percebe a própria empresa como uma parceira social.

Quando é relatado nas informações colhidas a preocupação com o mercado consumidor, é perceptível a fundamentalidade preservação tanto dos clientes da empresa, como também dos próprios colaboradores, construindo a melhor imagem da organização, como foi relatado pelos sujeitos pesquisados, condizendo com a Responsabilidade Social conforme Dias (2011).

QUADRO 04: Impacto pessoal e profissional

\begin{tabular}{|c|c|c|}
\hline Sujeito & Discurso Direto & Análise do Discurso Individual \\
\hline G1 & $\begin{array}{l}\text { "Como pessoa me sinto com uma sensação de } \\
\text { dever cumprido por estar envolvido em um } \\
\text { processo que tem como principal objetivo } \\
\text { produzir em alta escala sem causar danos ao } \\
\text { meio socioambiental, sendo totalmente } \\
\text { responsável pelas suas ações. Como } \\
\text { profissional há uma consciência de que minha } \\
\text { profissão é responsável por tentar reduzir ao } \\
\text { máximo os danos a sociedade e ao meio } \\
\text { ambiente, me sinto feliz em trabalhar em uma } \\
\text { empresa preservadora do meio ambiente e em } \\
\text { todo o tempo que atuo na organização venho } \\
\text { aprendendo cada vez mais a importância de ser } \\
\text { responsável". }\end{array}$ & $\begin{array}{l}\text { O sentimento pessoal do entrevistado é } \\
\text { denotado com muita satisfação, pelo fato de } \\
\text { estar contribuindo de maneira direta para a } \\
\text { preservação socioambiental, no entanto não } \\
\text { perde a visão administrativa almejando } \\
\text { sempre o objetivo de produzir, mas de } \\
\text { maneira consciente. } \\
\text { Profissionalmente existe uma conotação } \\
\text { semelhante a pessoal, o diferencial é } \\
\text { exatamente por relatar que se sente realizado } \\
\text { pela sua profissão ser também reconhecida } \\
\text { como uma preservadora do meio ambiente. }\end{array}$ \\
\hline G2 & $\begin{array}{l}\text { "Impacta de maneira direta tendo em vista que } \\
\text { contribuir com ações uma sociedade melhor é } \\
\text { importante, usando melhor os recursos } \\
\text { ambientais. A gestão deve ser usada de forma } \\
\text { inteligente, com a participação efetiva e ativa de } \\
\text { seus colaboradores e o consumidor vai } \\
\text { encontrar um produto de uma empresa que se } \\
\text { preocupa com a sociedade em meio ambiente". }\end{array}$ & $\begin{array}{l}\text { Mais uma vez é citada a retirada consciente } \\
\text { de recursos da natureza, que é fundamental na } \\
\text { responsabilidade da empresa. Falando da } \\
\text { ideia de gestão, ele relata sobre o papel da } \\
\text { gestão, que precisa ser utilizada de forma } \\
\text { inteligente para que essas ações não se } \\
\text { limitem apenas a determinados setores da } \\
\text { empresa e sim que todos os colaboradores se } \\
\text { sensibilizem, só o trabalho poderá ser efetivo. }\end{array}$ \\
\hline
\end{tabular}




\begin{tabular}{|c|l|l|}
\hline $\mathbf{G 3}$ & $\begin{array}{l}\text { "Sentimento de satisfação em ver que essa } \\
\text { empresa não oferece apenas produtos, mas } \\
\text { começa a ser vista como parte importante para } \\
\begin{array}{l}\text { o crescimento da sociedade na qual está } \\
\text { inserida e parceira na preservação e e } \\
\text { manutenção dos recursos ambientais". }\end{array}\end{array}$ & $\begin{array}{l}\text { Nesta fala é possível reparar a satisfação } \\
\text { umo empresa responsável, por outro lado, } \\
\text { também percebe-se mais uma vez uma } \\
\text { preocupação com a ideia de ser uma empresa } \\
\text { parceira da sociedade, mais uma vez usando } \\
\text { a RSE estrategicamente dentro da } \\
\text { organização. }\end{array}$ \\
\hline $\begin{array}{l}\text { Análise Coletiva } \\
\text { que se sentem felizes por fazer parte de uma empresa que está cuidando do meio ambiente e das futuras } \\
\text { gerações. Pode-se perceber também uma semelhança nas visões, o que vem a diferenciá-las é a especificação } \\
\text { da satisfação de cada, quando o primeiro especifica sua realização denotando a sua profissão de administrador, } \\
\text { enquanto outro já vislumbra um contento quando fala na gestão inteligente que consegue comover todos os } \\
\text { setores da corporação a um bem comum, como também é relatado visão do último sujeito o desejo e felicidade } \\
\text { em ser considerado juntamente com seu empregador como um parceiro da sociedade. }\end{array}$ \\
\hline
\end{tabular}

Fonte: Dados da Pesquisa (2017)

É bem notória a satisfação por parte de quem gere a empresa, foi citado acima a sensação de felicidade de conseguir fazer uma gestão responsável, que consegue manter a produção em alta escala, mas sem causar danos aos meios socioambientais, como é citado no conceito de empresa responsável de Aligreli; Aligreli; Kruglianskas (2009).

A ideia acima referida, quando se diz que para se chegar ao objetivo é preciso sensibilizar todos os setores da empresa a um bem comum que seria a preservação do meio ambiente sem perder a sua lucratividade, promovendo uma gestão inteligente, é completada pela teoria de Reynaud (2008), quando discorre sobre o modelo de Freeman de 1984. Quando é visível a toda a empresa e sociedade que as ações promovidas são o que garantem o bom funcionamento dos processos é que a empresa passa a ser vista como responsável, segundo este modelo, é esta a satisfação relatada acima quando se diz que a empresa passa a ser considerada uma parceira social.

\section{Considerações Finais}

Percebendo-se a competitividade nos mercados, esta pesquisa propôs como objetivo geral identificar a importância da estratégia como prática de responsabilidade socioambiental do ponto de vista dos gestores de uma empresa fabricante de materiais de limpeza, localizada 
na cidade Juazeiro do Norte - CE. Ao longo do estudo foram feitas visitas à empresa, onde foram entrevistados gestores de diferentes setores, buscando-se informações relativas ao objetivo. Foram colhidos dados baseados em diversos relatos e diversas informações acerca do tema foram obtidas.

Após tratamento das informações, através de uma análise de discurso que tratou de forma individual cada uma, foi realizado um cruzamento de informações de maneira geral e foi possível chegar a conclusões relativas ao que se buscou.

Ficou claro, que após a análise das várias opiniões colhidas que a responsabilidade social é de fundamental importância na empresa objeto do estudo, principalmente pela proporção do impacto que esta causa na visão do cliente, de acordo com os gestores. Foi percebido o quanto é grande a preocupação por parte da empresa em fortalecer a cultura da responsabilidade socioambiental nos seus processos, não abrangendo somente os colaboradores, mas também os clientes e toda a sociedade em torno da organização.

Pôde-se perceber que a responsabilidade social traz para a organização uma melhor imagem junto aos clientes, pois desenvolve práticas que almejam o crescimento da sociedade em conjunto com a empresa, principalmente pelo fato de que constrói uma ideia positiva na mente do stakeholder cliente, proporcionando com isso um crescimento no potencial da imagem da empresa, tornando esta referência para as demais atuantes do mercado. Além disso, ficou identificado que a empresa, tem uma facilidade bem maior de se posicionar dentro do mercado, pois consegue pela eficiência das suas ações ter uma considerável influência que não se limita apenas a clientes e empregados, mas que também engloba governo, instituições e toda a sociedade em geral.

Apenas preço, produto e qualidade não são mais fatores de diferencial competitivo, o cliente também precisa perceber que a marca que está comprando trabalham visando a redução dos danos ambientais e sociais causados por suas operações. Ou seja, segundo Tachizawa (2005), a imagem que a organização passa para o consumidor em relação à sua ética social tornou-se um importante critério de escolha para os clientes, superando muitas vezes aspectos como preço e qualidade dos produtos ou na prestação de serviços.

Dentre as práticas citadas pelos gestores, a que mais se destacou entre os relatos foi a reciclagem, seja ela da água utilizada na produção, como também de lixo produzido dentro dos processos, contudo a ação da organização que mais chamou a atenção pela sua abrangência e eficiência é a coleta de óleo de cozinha que é feita pela empresa, nos domicílios da cidade, 
como também em bares e restaurantes devidamente cadastrados, onde com essa ação toda a renda captada é revertida em doação para uma instituição local que auxilia crianças. São essas ações que configuram a filantropia social por partes das empresas, que é um dos pilares da responsabilidade social empresarial.

Depois de toda a análise feita de dados e informações ficou evidente a eficiência da responsabilidade utilizada como fator competitivo, levando em conta a repercussão que esta causa na empresa não apenas no atuar profissional dos colaboradores, mas também ao atingir o pensamento destes como pessoas, como foi relatado pelos entrevistados que depois de vivenciar diariamente essas práticas dentro do seu trabalho, isso o acompanha para casa, para a rua, ou seja, está na mente dos colaboradores a importância de promover essas atitudes não só no ambiente de trabalho, mas em todo e qualquer lugar.

Ao fim deste trabalho pode-se concluir o quanto é benéfico para uma organização a responsabilidade socioambiental como fator estratégico de crescimento, não apenas por proporcionar uma melhor imagem da organização frente aos seus clientes, mas também por que é possível estabelecer dentro dos processos produtivos ideias de preservação ambiental que que fazem parte da vida profissional e pessoal dos seus colaboradores.

Fica ainda o desejo e sugestão que mais estudos sejam feitos acerca deste tema tão importante, observando o quanto é necessário que haja mais preocupação de todos com os cuidados e com a preservação não só do meio ambiente, mas também do meio social, que precisa sempre de atenção das pessoas, empresas e governantes.

\section{Referências}

ACQUIER, A.; AGGERI, F.: Une genealogie de la pensée manageriale sur la RSE. Revue Française de Gestion, v. 38, n. 180, p. 131-157, 2008. Disponível em: <http://www.cairn.info/revue-francaise-de-gestion-2007-11-page-131.html>. Acesso em: 15 set.2016.

ALIGRELI, L.; ALIGRELI, L. A.; KRUGLIANSKAS, I. Gestão Socioambiental: Responsabilidade e Sustentabilidade do Negócio. São Paulo: Atlas, 2009.

ANDRADE, M. A. M.; GOSLING, M.; JORDÃO, R. V. D.: Responsabilidade social de siderúrgicas mineiras e a percepção de suas comunidades de entorno. Produçãa. v. 23, n. 4, p. 
793-805,

out./dez.

2013.

Disponível

em:

<http://www.scielo.br/pdf/prod/v23n4/aop_t6_0007_0709.pdf>. Acesso em: 14 set.2016.

BRASIL. Conselho Nacional de Saúde - Resolução 510/2016 de 07 de abril de 2016. Disponível em: <http://conselho.saude.gov.br/resolucoes/2016/Reso510.pdf>. Acesso em 15 nov.2016.

DIAS, Reinaldo. Gestão Ambiental: Responsabilidade social e sustentabilidade. 2 ed. São Paulo: Atlas, 2011.

FADINI, P. S.; FADINI, A. A. B. Lixo: desafios e compromissos. 2005. Disponível em: <http://sbqensino.foco.fae. ufmg.br/uploads/314/lixo.pdf>. Acesso em: 10 dez.2016.

FREITAS, Juarez. Sustentabilidade: direito ao futuro. Belo Horizonte: Fórum, 2012.

GIL, Antônio Carlos. Como elaborar projetos de pesquisa. 5 ed. São Paulo: Atlas, 2010.

MASSUKADO, L. M. Sistema de Apoio a Decisão: avaliação de cenários de gestão integrada de resíduos sólidos urbanos domiciliares. São Carlos: UFSCar, 2004. Disponível em: <http://www.bdtd.ufscar.br/htdocs/tedeSimplificado/tde_arquivos/11/TDE-20041213T14:54:34Z-342/Publico/DissLMM.pdf>. Acesso em: 15 dez.2016.

MENDES, J. M. G. Dimensões da Sustentabilidade. v. 7, n. 2, julho/dezembro 2009. Revista das Faculdades Santa Cruz. Disponível em: <http://www.santacruz.br/v4/download/revistaacademica/13/cap5.pdf >. Acesso em: 14 nov.2016.

OLIVEIRA JR. P. F. P; PACAGNAN, M. N.; MARCHIORI, M. Contribuições da Metodologia do Discurso do Sujeito Coletivo (DSC) para Investigação da Estratégia como Prática. 2013. Disponível em: <http://www.uel.br/grupoestudo/gecorp/images/discurso_do_sujeito_coletivo.pdf>. Acesso em: 15 maio.2017.

REYNAUD, E. et al.: La responsabilité sociale de l'entreprise à l'épreuve de l'Europe, n. 180, p. 109-130, 2008/1. 2008. Revue Française de Gestion. Disponível em <http://www.cairn.info/article.php?ID_ARTICLE=RFG_180_0109>. Acesso em: 16 set.2016.

SCHOLL, C. A.; HOURNEAUX JR. F.; GALLELI, B. Sustentabilidade organizacional: aplicação de índice composto em uma empresa do setor químico. Gest. Prod., São Carlos, v. 22, n. 4, p. 695-710, 2015. Disponível em: <http://www.scielo.br/pdf/gp/v22n4/0104-530X-gp0104-530X1343-13.pdf>. Acesso em: 14 nov.2015.

SOARES, L. G. C.; SALGUEIRO, A. A.; GAZINEU, M. H. P. Educação ambiental aplicada aos resíduos sólidos na cidade de Olinda, Pernambuco - um estudo de caso. Recife: Universidade Católica de Pernambuco, 2007. Disponível em: <http://www.unicap.br/revistas/revista_e/artigo5.pdf>. Acesso em: 29 nov.2016.

TACHIZAWA, T. Gestão Ambiental e Responsabilidade Social Corporativa: Estratégias de negócios focadas na realidade brasileira. 3 ed. São Paulo: Atlas, 2005. 
VAZ, J.C.; CABRAL, C. C. Desenvolvimento urbano. Disponível em: $<$ http://federativo.bndes.gov.br/dicas/ D001$\% 20$ Coleta\%20seletiva\%20e\%20reciclagem\%20do\%20lixo.htm>. Acesso em: 10 dez. 2016.

WCED - World Comission on Environment and Development. (1987). Our common future: the Brundtland report. Oxford: Oxford University Press. Disponível em: <https://ambiente.files.wordpress.com/2011/03/brundtland-report-our-common-future.pdf>. Acesso em: 14 nov.2016.

ZANITELLI, L. M. Capitalismo Brasileiro e Responsabilidade Social Empresarial, n. 66, p. 83112, jul. 2013. Sequência (Florianópolis). Disponível em: $<$ https://periodicos.ufsc.br/index.php/sequencia/article/view/2177-

7055.2013v34n66p83/25061>. Acesso em 17 set.2016.

\section{Como citar este artigo (Formato ABNT):}

LOPES, José Henrique da S.; MEDEIROS, Adriana V.; ALENCAR, Maria Patrícia de; ALMEIDA NETO, José Leandro de. Análise da Importância da Responsabilidade Socioambiental como Fator Competitivo em uma Fábrica de Material de Limpeza em Juazeiro do Norte - CE. Id on Line Revista Multidisciplinar e de Psicologia, 2018, vol.12, n.40, p.59-77. ISSN: 1981-1179.

Recebido: 11.02 .2018

Aceito: 14.02 .2018 